\title{
The intentions, needs, advantages and barriers: a survey of twenty-nine countries participating in the "Belt and Road Initiative" health cooperation
}

\author{
Yao Wang ${ }^{1}$, Xiaohui Liang ${ }^{1}$, Yuchen Liu², Yuanan Lu³, Xiaojun Liu ${ }^{1}$ and Zongfu Mao ${ }^{1 *}$
}

\begin{abstract}
Background: China launched the Belt and Road Initiative (BRI) aiming to develop a mutually-beneficial, sustainable trade model with partner countries. The processes of international health exchanges are key parts of how this model can be sustained into the future. This paper aims to contribute to broader understanding by exploring various intentions, needs, advantages and barriers of BRI countries and then define ways China can achieve better health cooperation.

Methods: In this study, a survey questionnaire was developed to investigate the perspectives of 60 international experts from $29 \mathrm{BRI}$ countries. The survey was distributed and collected during the "Belt and Road High-level Meeting for Health Cooperation", held in Beijing in August 2017. The data were entered into EpiData 3.0 by two team members respectively and analyzed with SPSS22.0.

Results: Altogether 58 valid questionnaires were obtained. More than $93 \%$ of participants showed their willingness to be part of BRI health cooperation. Frist, three key areas were identified, which are broadly defined as BRI country "needs": (1) "Develop health industries"; (2) "Prevent and control infectious diseases"; and (3) "Provide health services". Second, three "advantages" of participating in BRI Health Cooperation were found: (1) "The establishment of a long-term partnership"; (2) "Quality investment and financing system"; and (3) "The convenience of cooperation". Third, two main cross-cultural "barriers" for cooperation were encountered: (1) "Cultural differences"; and (2) "Lack of communication platforms".

Conclusion: In this study, we have identified priority fields that China can collaborate with BRI countries and show its leadership. It is suggested that successful health cooperation between China and other BRI countries should focus on maximizing present health-industry partnerships, investment and financing, as well as overcoming cultural and communication barriers.
\end{abstract}

Keywords: Belt and road initiative, Health cooperation, Needs, Advantages, Barriers

\footnotetext{
*Correspondence: zfmao@126.com

'Global Health Institute/School of Health Sciences, Wuhan University, Wuhan

430061, China

Full list of author information is available at the end of the article
}

(C) The Author(s). 2019 Open Access This article is distributed under the terms of the Creative Commons Attribution 4.0 International License (http://creativecommons.org/licenses/by/4.0/), which permits unrestricted use, distribution, and reproduction in any medium, provided you give appropriate credit to the original author(s) and the source, provide a link to the Creative Commons license, and indicate if changes were made. The Creative Commons Public Domain Dedication waiver (http://creativecommons.org/publicdomain/zero/1.0/) applies to the data made available in this article, unless otherwise stated. 


\section{Introduction}

The Belt and Road (B\&R) is the abbreviation of the Silk Road Economic Belt and the twenty-first Century Maritime Silk Road. In 2013, Chinese President Xi first put forward the Belt and Road Initiative (BRI), which aimed to develop cooperative partnerships with countries along the Belt and Road, and jointly build a community of interests, destiny and responsibility. At present, BRI has been supported by lots of countries and have expanded beyond the $B \& R$ boundaries to the world. One of the most important parts of BRI is health cooperation, which can be called BRI Health Cooperation and carries China's commitment to BRI countries. BRI Health Cooperation is best illustrated by China's "Three-Year Plan for the Implementation of the 'Belt and Road Initiative' Health Exchange and Cooperation (2015-2017)" (hereinafter referred to as the "Implementation Plan"). This plan, now shifting from a period of infancy to a more mature international presence, has already implemented 41 major projects and activities, with positive commercial and reputation outcomes [1,2]. Beyond these initial steps of international health cooperation via the BRI framework, though, what is clear is the significant role China will take in directing future international health cooperation. It can be seen that the projects and activities China have already implemented with other BRI countries represent a foreshadowing of a profound change to global health governance.

However, these initial successes, and the continued expansion of BRI and participating country numbers [3], belie the various barriers that BRI Health Cooperation faces. Much of the current cooperation plans, projects and activities continue in a phase of infancy. China's strategy of beginning health cooperation programs with important fulcrum countries that have strong political foundations and a base of cooperation [4] has inevitably led to decentralized health cooperation. Other challenges range from insufficient forms of cooperation to weak continuity of cooperation content [5]. At the same time, broader health cooperation issues have come to light, including the indistinct relationship of supply and demand, slow timeline of cooperation decisions, and weak cooperation initiatives. So, just as China's role in shaping the direction of future global health governance is clear, China will need to better identify and understand the intentions, needs, advantages and barriers of partnership countries to achieve more efficient and sustainable processes of health cooperation.

Scholarly explorations of the BRI have mainly focused on analyzing the intention of BRI Health Cooperation. Explorations taken from a primarily Chinese perspective mostly focus on summarizing and comparing certain areas of health cooperation, notably health systems and policies, traditional medicine, infectious disease prevention and control, ability improvement and personnel training, and health development assistance [6, 7]. As such, there are gaps in scholarly research. These gaps are to do with the ways cooperation among countries along Belt and Road (B\&R) is developing, including an understanding of their health industry needs. This study is designed to begin filling these gaps. It is intended as a step toward a deeper appreciation of the key factors shaping BRI Health Cooperation: intentions, needs, advantages and barriers. Results from the study can be taken as baseline information for decision makers and participants in health cooperation.

\section{Methods}

\section{Context and study sample}

In August 18-19, 2017, the "Belt and Road High-level Meeting for Health cooperation: towards a Health Silk Road" was organized by the National Health Commission (NHC) of the People's Republic of China (P.R.C.) in Beijing. Participants were composed of government officials, representatives of international organizations such as the United Nations and the World Health Organization, as well as representatives of relevant government departments, scientific research institutions, non-governmental organizations, think tanks, and enterprises. Altogether 60 international experts participated in the study with the assistance of the International Exchange and Cooperation Center, NHC, P.R.C.

\section{Survey questionnaire}

The survey has been approved by the Medical Ethics Committee of Wuhan University School of Medicine. The "Belt and Road' National Health Cooperation Intention Survey" questionnaire was adapted from the "China-Africa Health Cooperation Intention and Needs Questionnaire" [8]. It was developed by Wuhan University Global Health Institute and went through several rounds of expert consultations. The questionnaire includes general information, such as country, unit, position, nature of the unit, and 10 items, including the cooperating country/province, cooperation area, cooperation intention and demand, and health cooperation advantages and barriers. It was adapted and developed according to "Belt and Road High-level Meeting for Health Cooperation: towards a Health Silk Road" conference participant characteristics.

\section{Data collection and processing}

Before the survey is launched, investigators were trained about the study. A pre-test trail was also conducted by two-person groups. During the investigation, a "one-toone" questionnaire survey method was taken up. It was distributed, answered, and collected upon completion. Once all the completed questionnaires were collected, 
they will be summarized, coded, and screened by an investigator. The criteria for questionnaire selection was based on the completion rate $\geq 80 \%$, with missing values replaced by a median option. If, in the case of two or more participants of the same position level in one unit or institution both/all filled out the questionnaires, selection priority was given to those who had more experience with international communication and cooperation. At last, all the survey results were entered twice by two investigators, simultaneously. Computer logic error detection was used to ensure an accurate completion of the final database. A total of 60 questionnaires were distributed and 58 of them were considered valid, making the effective rate of the questionnaire reach $96.7 \%$. As a result, the 58 questionnaires were collected and analyzed for our study purpose.

\section{Statistical analysis}

The data was statistically analyzed using SPSS 22.0. The qualitative data is represented by frequency, and rate or composition ratio for statistical description.

\section{Results}

The 58 participants were from 29 countries around the world: Africa (11 nations), Asia (9 nations), Europe (3 nations), North America (5 nations) and South America (1 nation). Among the 58 participants, 24 were from Asia (41.4\%), 3 from Europe and 1 from South America. Considering the relatively low participation from Europe, North America and South America (that is, a total of 15 people, accounting for $25.9 \%$ of the total number of survey), these participants are referred to as a collective titled, "Western countries".

The participants were more often associated with "Government departments" and "Medical institutions", and they accounted for $67.2 \%$ of the total number. In comparison, "Universities and research institutes", "Enterprises", and "International organizations" accounting for only $32.7 \%$ (Table 1 ).

\section{Willingness to BRI health cooperation}

More than $90 \%$ of participants expressed interest in BRI Health Cooperation. In comparison, only $3.4 \%$ of participants, or two participants, said they would not be a part

Table 1 Unit nature of the participants

\begin{tabular}{ll}
\hline Unit nature & $\mathrm{N}(\%)$ \\
\hline Government departments & $22(37.9)$ \\
Medical institutions & $17(29.3)$ \\
Universities and research institutes & $10(17.3)$ \\
Enterprises & $5(8.6)$ \\
International organizations & $4(6.9)$ \\
Total & $58(100.0)$ \\
\hline
\end{tabular}

of BRI Health Cooperation (Table 2), specifically a scholar from the United States and a Centers for Disease Control (CDC) official from Sudan. Two participants from Georgia, a nurse and an international staffer, indicated that they were not sure whether their countries had any intention to participate.

\section{The needs for BRI health cooperation}

One of the key results of the questionnaire survey, "needs", shows participants views on where and what BRI Health Cooperation should focus its attention on. A large number of participants believed the most important areas for cooperation were "Health industry" (48.3\%), "Health Services" (44.8\%), and "Prevention and Control of infectious diseases" (43.1\%). The demand for "Traditional medicine" cooperation was found to be the lowest "need". Notably, participants also suggested a "need" to establish a sustainable food system, a subject included in the "Other" categorization (Table 3).

\section{Regional needs}

The survey also registered the "needs" associated with each specific region. For example, according to the survey, the greatest health cooperation "needs" in Asia are "Health services" (22.8\%), "Prevention and control of infectious disease" (19.3\%), and "Health industry" (15.8\%). "Traditional medicine" (1.8\%) was identified as being a non-priority "need". For African and Western countries, the greatest "need" was "Health industry". The second and third "needs" for these areas were "Prevention and control of infectious diseases" (20.9\% and 19.4\%, respectively), and "Health services" (14.0\% and 19.4\%). Neither area expressed a "need" to cooperate on "Health Emergency/Emergency medical assistance” (Fig. 1).

\section{Advantages of BRI health cooperation}

According to the participants, the three key advantages of health cooperation were (1) establish a "Long-term partnership" with China, (2) "A good investment and financing system" and (3) take advantage of the "Convenience of cooperation". Conversely, issues such as "Preferential policies" and "Geographical advantages" were considered relatively disadvantageous, both $5.2 \%$ (Table 4).

Table 2 willingness of participation in BRI Health Cooperation

\begin{tabular}{ll}
\hline Options & N (\%) \\
\hline Yes & $54(93.2)$ \\
No & $2(3.4)$ \\
Not clear & $2(3.4)$ \\
Total & $58(100.0)$ \\
\hline
\end{tabular}


Table 3 Contents of participation in BRI Health Cooperation

\begin{tabular}{ll}
\hline Contents & $\mathrm{N}(\%)$ \\
\hline Health industry & $28(48.3)$ \\
Health Services & $26(44.8)$ \\
Prevention and control of infectious disease & $25(43.1)$ \\
International development assistance & $16(27.6)$ \\
Personnel training / medical research & $14(24.1)$ \\
Health emergency / emergency medical assistance & $11(19.0)$ \\
Health care management & $8(13.8)$ \\
Traditional medicine & $2(3.4)$ \\
Others & $1(1.7)$ \\
\hline
\end{tabular}

\section{Regional advantages}

The most important regional advantages were "Longterm partnerships" and "Good investment and financing systems". Western countries considered "Long-term partnerships" to be more significant (40.0\%). They also considered "Public acceptance to China" (12.0\%) to be of greater advantage than Africa (7.1\%) and Asia (2.2\%). Each region identified "Preferential policies" and "Geographical advantages" as being a relatively low "advantage" (Fig. 2).

\section{Barriers for BRI health cooperation}

The major BRI Health Cooperation barriers, as noted by the survey respondents, were considered to be "Cultural differences" (34.5\%) and "Lack of communication platforms" (32.8\%). Conversely, the respondents considered "Legal challenge" (6.9\%) and "Stability of policy environment" (6.9\%) to be minor barriers. Another minor barrier, one not initially listed on the survey, was "Language barrier" (see "Other": 5.2\%), which the correspondents held that they were cognizant of during entire Sinoforeign cooperation projects (Table 5).
Table 4 Advantages of participating in BRI Health Cooperation

\begin{tabular}{ll}
\hline Advantages & $\mathrm{N}(\%)$ \\
\hline Long-term partnership & $34(58.6)$ \\
A good investment and financing system & $24(41.4)$ \\
Convenience of cooperation & $18(31.0)$ \\
Medical services and product quality and reputation & $15(25.9)$ \\
The influence of Chinese traditional medicine & $9(15.5)$ \\
People's acceptance to China & $7(12.1)$ \\
Preferential policies & $3(5.2)$ \\
Geographical advantages & $3(5.2)$ \\
\hline
\end{tabular}

\section{Regional barriers}

In terms of regional specific responses, the Asian participants identified "Cultural difference" (25.6\%), "Lack of communication platform" (20.5\%), and "Lack of e-trade platform" (12.8\%) as the major barriers of BRI Health Cooperation. For the Western country participants, the major barriers were similarly "Cultural difference" (21.7\%) and "Lack of e-trade platform" (17.4\%), as well as "Drug quality and certification issues" (17.4\%). For the African participants, the greatest barriers were "Lack of communication platform" (23.5\%), "Cultural difference" (14.7\%), and "Complex application procedure" (14.7\%) (Fig. 3).

\section{Discussion}

\section{Broad prospects of BRI health cooperation}

Since 1963, China has started to dispatch China Medical Team (CMT) on two-year rotations to provide clinical care in low-resource settings around the world, most of them in Africa. The program continues today in an expanded form: at any given time, more than 1000 staff are deployed abroad at an estimated cost of US\$60 million annually [9]. This status reflects the critical shift in

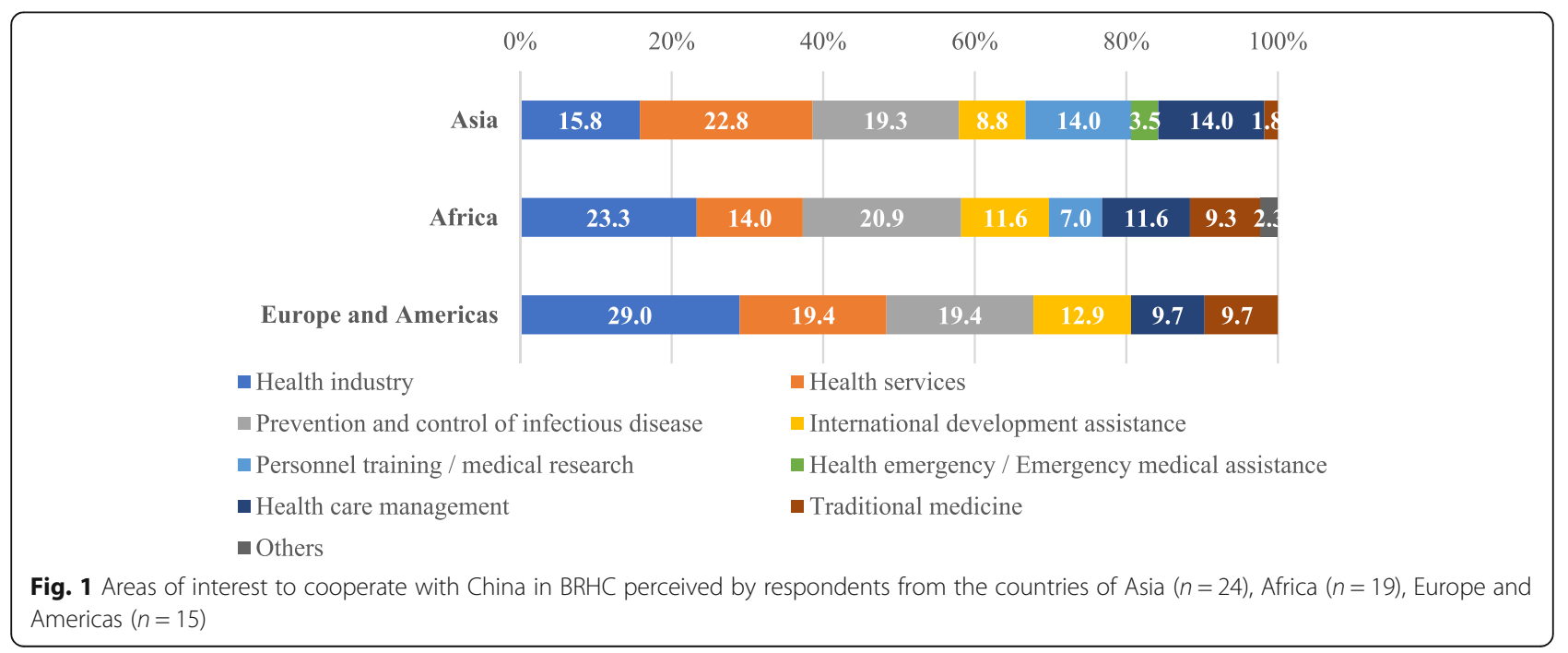




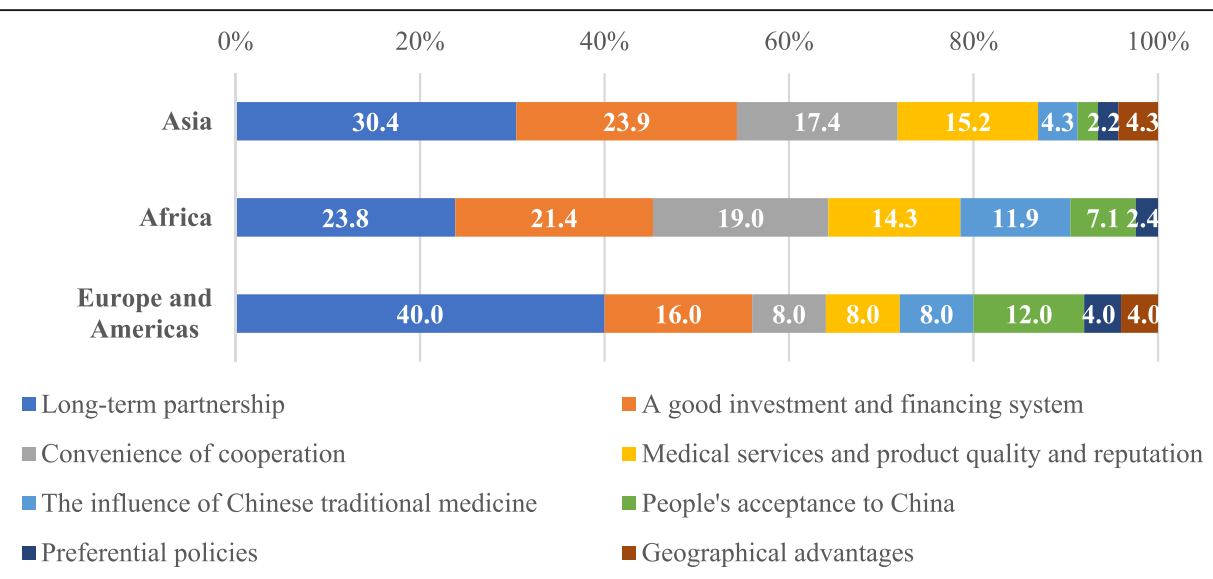

Fig. 2 Advantages perceived by respondents from the countries of Asia $(n=24)$, Africa $(n=19)$, Europe and Americs $(n=15)$ on their countries' participation in BRHC with China or the reasons for choosing China as the partner

China's role over the last decade from being an aid recipient to a non-conventional donor in global development aid; which is to reflect back on the fact that China is now playing an increasingly crucial role in global health development $[10,11]$.

In this context, our results highlight an overwhelming preference for cooperation (over 93\%), which is notable on a number of levels, not least for the stark contrast it provides when viewed against recent global events and trends: as in, an economic recession in Europe, a rising trend toward anti-globalization, war and chaos in West Asia, and an economic downturn in Africa [12]. As such, the preference denotes an increase in BRI and its promise of greater cooperation significance. A consequence of this is to make BRI Health Cooperation standout in positive ways to policymakers, industry practitioners and patients. At the same time, most countries along $B \& R$ are yet to develop their economics, and the political and security situations in some of them continue to be turbulent [13]. Undoubtedly, these situations pose significant barriers for the development of local health services, one that outside sources can potentially remedy.

Table 5 Distribution of barriers in BRI Health Cooperation

\begin{tabular}{ll}
\hline Barriers & $\mathrm{N}(\%)$ \\
\hline Cultural difference & $20(34.5)$ \\
Lack of communication platform & $19(32.8)$ \\
Lack of e-trade platform & $11(19.0)$ \\
Lack of funds & $10(17.2)$ \\
Drug quality and certification issues & $10(17.2)$ \\
Complex application procedure & $8(13.8)$ \\
Lack of government support & $7(12.1)$ \\
The stability of the policy environment & $4(6.9)$ \\
Legal challenge & $4(6.9)$ \\
Others & $3(5.2)$ \\
\hline
\end{tabular}

In other words, the conditions are present in which a sustainable uptake of BRI Health Cooperation can be achieved, which is a point-of-view most notably cast by the "needs" of developing countries and "advantages" for a new player, such as China, to emerge on the global health stage.

\section{Priority "needs" of BRI health cooperation}

Our findings highlighted several key areas that the BRI Health Cooperation should prioritize, which include health industry, medical and health services and infectious disease prevention and control. Unsurprisingly, these "needs" align with the "Healthy China 2030 Planning Outline" [14] and "Implementation Plan" [4]. Other important "need" areas concern health-related industries, specifically the strength of industry development and cooperation to produce and maintain, among many products, pharmaceuticals and medical devices, health foods, medical tourism and health information construction [15].

This medical and health services development and cooperation will likely stimulate consumer demand and promote the growth of service trade along $B \& R$, which is undoubtedly a good way to engage populations while safeguarding their health [16]. An example of this cooperation is the hospital alliance between China and Central and Eastern European countries, where joint research and treatment of intractable diseases are engaged, allowing the respective publics to enjoy the highest level of medical diagnosis and treatment at home [17].

Other areas of development and potential cooperation include Chinese traditional medicine and protection and control of infectious diseases. Chinese traditional medicine technology and services are likely to evolve in relation to BRI Health Cooperation development, with Chinese medicine acupuncture already adopted and adapted in 183 countries and regions worldwide [18]. In 


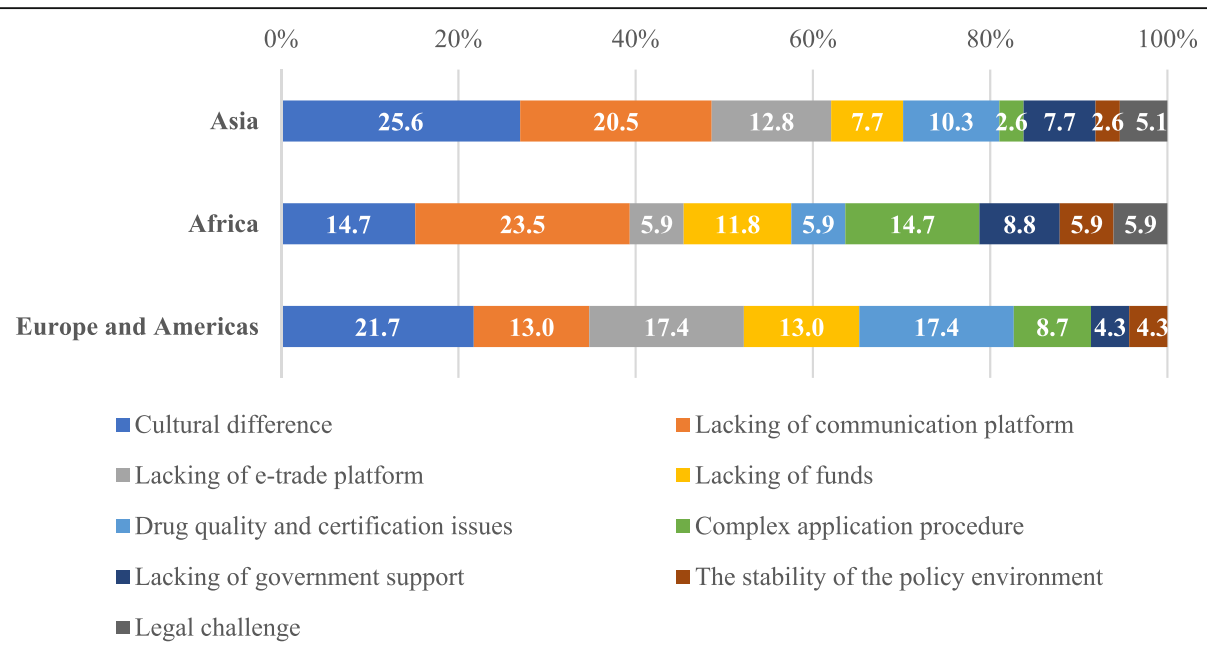

Fig. 3 Barriers perceived by respondents from Asia $(n=24)$, Africa $(n=19)$, Europe and the Americas $(n=15)$ on their countries 'participation in $B R H C$

terms of infectious diseases, globalization trends mean these diseases need to be taken more seriously; or the alternative is to risk a global health crisis. In the past decade, China has carried out a series of cooperation projects with Laos, Vietnam, Myanmar, and other countries along $B \& R$ that targeted malaria, dengue fever, AIDS, and other infectious diseases. Greater BRI Health Cooperation will inevitably expand these prevention and control projects, leading to stronger, more consistent health outcomes.

\section{Important factors in promoting BRI health cooperation} Significantly, the "needs" correspond to many of our findings for "advantages". A summary of the key "advantages" highlights long-term partnerships, and good investment and financing systems. These advantages reflect the broader importance of taking a multi-layer approach to international cooperation. An illustration of how this is currently being achieved is the Asian Infrastructure Investment Bank (AIIB), which, since 2014, has become an embodiment of China's international perspective of openness and economic reform, and, importantly, presents clearer institutional pathways for health to connect with diplomacy, economics, politics, and other fields of international exchange. This notion of layering is also useful when considering the function of already established cooperative partnerships. These partnerships will serve as a favorable model for other future cooperation activities [19]. Here, the idea for international cooperation is to prioritize partners with existing cooperation bases and ensure continued, smooth financial support.

In this context the acceptance of China as a key player as well as the relative locations of partner countries to China are significant issues to consider. Western governments and institutions may play a role in promoting BRI Health Cooperation, although the geographical distance from China means the specifics of their role is less clear. In contrast to this point, our findings showed that countries had low perceptions of geographical advantages and preferential policies. Even though the neighboring Asian countries are the starting countries of $\mathrm{B} \& \mathrm{R}$, cross-border cooperation may remain a major challenge. Surprisingly, our results show that the Asian countries consider their geographical advantage to be weak, while both the African and Western countries consider it even weaker. These results are similarly reflected in terms of preferential policies. That is, despite China's governments of all levels on international health cooperation issuing a series of relevant preferential policies, international awareness of these policies is still low (which may be related to the insufficient spillover effect of domestic preferential policies). It is advised that the Chinese government departments take the geopolitical gaps into account when developing a specific policy, publicize the policy to international partners based on sufficient understanding of cultural differences, so as to further facilitate deeper health cooperation among China and its partners.

\section{Major barriers of BRI health cooperation}

It is found in our findings that both Asia and Western countries considered "Cultural differences" to be the biggest barrier for health cooperation. This barrier has been explored by some Chinese studies [20, 21]. In Africa, the biggest barrier was identified as "Communication platform". More specifically, sector-oriented barriers were also analyzed, although similar results were found. For example, in the professional interaction process of diagnosis and treatment, culture is considered to be more 
significant than professional knowledge. In international trade activities, cultural differences are considered to be a factor in negative trade flow outcomes [22]. These results suggest that in international health exchanges, cultural differences in different countries may become a major barrier for cooperation. Undoubtedly, the lack of communication platforms, as highlighted in the African results of the survey, is a contributing factor in this barrier, particularly when considering the benefits of a continuous flow of information between international parties. In the same way, the main barriers identified by Europe and the United States, that is, a lack of international electronic trading platforms, define other barriers relating to "exchange", albeit ones to do with trade instead of communication.

The differences in these barriers may derive from the differences in economic development of those areas [23]. In terms of resolving communication and e-commerce platform barriers, China's participation in South-South cooperation and China-Africa cooperation provides a platform for international exchanges and cooperation, but the areas are limited to infrastructure construction, energy and environment, business development, human resources, health education, and so on [24]. Given this gap in platform coverage, it is clear a normalization mechanism for large-scale exchange activities in the health field should be established. It is also advisable that China make an effort to develop cross-border medical ecommerce platforms with countries in Europe and North and South Americas. It is conceivable that the Alibaba Group, for example, which established the mobile third-party payment tool "Alipay" when developing the Taobao system in 2003 [25], could be expanded to facilitate health-based trade. However, as noted above, it would mean an integrative process based on mutual understanding, including cultural and communicative factors. This returns the discussion to the key argument of this article: understanding the various factors, including "needs", "advantages" and "barriers", in international health cooperation is crucial.

\section{Limitations}

The main limitation of the study was the sample size. The international participants in the conference were Ministers and higher rank officials. They provided a strong understanding of their national conditions and health development plans. However, the relatively small sample size meant it was difficult to avoid instances of personal opinion that could be deemed "biased". Research that documents a larger sample size would help reduce the impact of this issue on the study. In addition, a greater number of countries would benefit the study, particularly when considering that BRI is an open concept involving all countries in the world.

\section{Conclusions}

In this study, we have identified priority fields that China can collaborate with BRI Countries and show its leadership, such as health industry, medical services, and infectious disease prevention and control. It is found that successful health cooperation between China and other BRI countries is largely dependent on maximizing present health-industry partnerships, investment and financing, as well as overcoming cultural and communication barriers. These findings are all based on a developed understanding of China and its BRI Health Cooperation partners, their needs, and thoughts on cooperation advantages and barriers.

\section{Abbreviations}

B\&R: Belt and Road; BRI: Belt and Road Initiative; CDC: Centers for Disease Control; CMT: China Medical Team

\section{Acknowledgements}

We would like to thank Zhongjun Bi and Yage Liu for revising the questionnaire, and Shan Lu and Sanyu Ge for helping during the survey, and Dave Hare for language editing.

\section{Author's contributions}

YW and XL had shared responsibility in developing initial literature search and writing this paper. ZM provided guidance throughout the research process. YW did the systematic review, conducted the survey and statistical analysis. YL translated the article into English edition. All authors reviewed the paper, provided critical feedback, and approved the final version to be published.

\section{Funding}

This study was financially supported by researching on health cooperation strategies between China and countries along B\&R project funded by International Health Exchange and Cooperation Center.

\section{Availability of data and materials}

The datasets used and/or analyzed during the current study are available from the corresponding author on reasonable request.

\section{Ethics approval and consent to participate}

We declare that the study was conducted after securing ethical clearance from the Medical Ethics Committee of Wuhan University School of Medicine, and obtaining consent from study participants.

\section{Consent for publication}

Not applicable.

\section{Competing interests}

We declare no competing interests.

\section{Author details}

${ }^{1}$ Global Health Institute/School of Health Sciences, Wuhan University, Wuhan 430061, China. ${ }^{2}$ High School of Nanjing Foreign Language School, Nanjing 210008, China. ${ }^{3}$ Department of Public Health Science, University of Hawaii at Manoa, Honolulu, HI 96822, USA.

Received: 8 December 2018 Accepted: 12 June 2019

Published online: 28 June 2019

\section{References}

1. XinHuaNet. Xi Jinping attended the opening ceremony of the "belt and road" international cooperation summit forum and delivered a keynote speech.2017.http://news.xinhuanet.com/world/2017-05/14/c_1120969549. htm. Accessed 15 Dec 2017.

2. National Health Commission of the People's republic of China. The "belt and road" health cooperation has been steadily advanced, and the "healthy 
silk road" has achieved fruitful results. 2017. http://jiankang.cctv.com/2017/ 05/12/ARTI3VfP9QgxK1BdUeEYXRnG170512.shtml. Accessed 15 Dec 2017.

3. Wang $Y$, Wang WJ, Fu C, et al. Research on the status and implication of the health cooperation between China and countries along "belt and road". Chinese Journal of Health Policy. 2018;11(10):56-61 in Chinese.

4. National Health Commission of the People's Republic of China. Three-year implementation plan for promoting the "belt and road" Health Exchange and Cooperation (2015-2017). 2015. http://www.cnsn.gov.cn/sfzggw/shsy/ 201511/7ec69573530b481f8cd9ebb27c595a78.shtml. Accessed 8 July 2018.

5. Wang YP. "Belt and road" health cooperation should uphold five principles. Health News. (006):2015-11-16 in Chinese.

6. Yilmaz S, Changming L. China's 'belt and road' strategy in Eurasia and euroAtlanticism. Europe-Asia Studies. 2018;70(2):252-76.

7. Ferdinand P. Westward ho-the China dream and 'belt and road': Chinese foreign policy under Xi Jinping. Int Aff. 2016:92(4):941957.

8. School of Health Sciences, Wuhan University. Global Health Newsletter 2017 NO8 (total issue 36th) http://shs.whu.edu.cn/info/1120/3418.htm. Accessed 15 Dec 2017.

9. Alcorn T. New orientation for China's health assistance to Africa. Lancet. 2015;386:2379-80

10. Shajalal M, Xu JF, Jing J, et al. China's engagement with development assistance for health in Africa. Global Health Research and Policy. 2017;2:24.

11. Fan VY, Grépin KA, Shen GC, et al. Tracking the flow of health aid from BRICS countries. Bull World Health Organ. 2016;92:457-8,

12. Dollar D. China rise as regional and global power - The AllB and the 'One Belt, One Road'.cirsd.2015. https://www.cirsd.org/en/horizons/horizonssummer-2015--issue-no4.

13. China Export \& Credit Insurance Corporation. The Handbook of Country Risk. Current Affairs Press, BeiJing:2015

14. The State Council the People's Republic of China. State council issued the "healthy China 2030" plan outline.2016.http://www.gov.cn/zhengce/201610/25/content_5124174.htm.Accessed 15 Dec 2017.

15. Chase-Lubitz JF. The corporate practice of medicine doctrine: an anachronism in the modern health care industry. Vanderbilt Law Rev. 1987; 40(2):445-88.

16. Mckimm J, Mannion H. Medical leadership--we need more good followers. Lancet. 2015:386(10003):1532

17. Pavlićević D. 'China threat' and 'China opportunity': politics of dreams and fears in China-central and eastern European relations [J]. Journal of Contemporary China. 2018;27(113).

18. Yang $Y$, Shen $Z, W u Z$, et al. Strategy programming for acupuncture development along One-Belt-one-road countries. Zhongguo Zhen Jiu. 2017; 37(4):343-8 in Chinese.

19. Kickbusch I, Silberschmidt G, Buss P. Global health diplomacy: the need for new perspectives, strategic approaches and skills in global health. Bull World Health Organ. 2007:85(3):230-2.

20. Wang Y, Fu C, Lu S, et al. Analysis on health cooperation intentions, demands, advantages and disadvantages among "belt and road" countries. Chinese Journal of Health Policy. 2018;11(10):51-5 in Chinese.

21. Napier AD, Ancarno C, Butler B, et al. Culture, inequality, and health-care delivery. Chinese Journal of Health Policy. 2016;9(03):74-81 in Chinese.

22. Song YM, Li Z, Yang $\mathrm{HL}$. Which is more important for cultural distance and spatial distance? Research on the influence of cultural differences on China's foreign trade. Macroeconomics. 2015;(09):88-97 in Chinese.

23. Ma L. International cooperation strategies in different states of China-Experience from World Health Organization. Bei Jing: Peking union medical college,2013. (in Chinese).

24. Olu O, Petu A, Ovberedjo M, et al. South-south cooperation as a mechanism to strengthen public health services in Africa: experiences, challenges and a call for concerted action. Pan African Medical Journal. 2017;28:40.

25. Surhone LM, Tennoe MT, Henssonow SF. Taobao,Mauritius: Betascript Publishing, 2011

\section{Ready to submit your research? Choose BMC and benefit from:}

- fast, convenient online submission

- thorough peer review by experienced researchers in your field

- rapid publication on acceptance

- support for research data, including large and complex data types

- gold Open Access which fosters wider collaboration and increased citations

- maximum visibility for your research: over $100 \mathrm{M}$ website views per year

At $\mathrm{BMC}$, research is always in progress.

Learn more biomedcentral.com/submissions 